\section{DISCLSSION}

Contrary to the experimental hy pothesis, the results of this experiment imply that perceivable body morement results in positive time-judgnent error. Such implications are in accordance with the findings of Woodrow (1933). which pose time perception or experiences of duration as dependent properties of sensory experiences.

Since the function of time perception cannot be assigned to a specific body mechanism (Bartley. 1958). a wide variety of controls are pertinent to insure exclusion of extraneous variables capable of affecting such a massive expanse of sensory receptors (Hirst. Pickford. \& Vibum. 1964). Such rigid controls were exercised in the present experiment with the exception of noise level. The noise produced by the rotation motor afforded a slightly higher-pitch noise level when uncoupled from the chair in control group reproductions than it did when coupled to the chair in the experimental group replications. Such a change in noise level has been found to shorten judgment of time intervals when using brief durations (Fraisse. 1963). However. the noise-level differences between control and experimental groups were significantly $(p<.05)$ less than that produced between 15 and 30 rotation levels.

It is pertinent to note the method of time judgment used in the present experiment. Arons \& London (1969) found that time-interval estimations were influenced by the method employed in the estimates. The results of studies conducted by Hornstein \& Rotter (1969) indicate that time intervals are underestimated when the method of reproduction is used. Such results enhance the significance of the positive error exhibited in the experimental groups. but are inconsistent with results obtained from the control group. However, the consistent positive error of the control group may be attributed to a reversal of spontaneous judgment. due to anticipated demands of the perceivable experimental situation (Arons \& London. 1969).

Although it is evident from the results of this experiment that bodily rotation induces positive time-judgment error, the magnitude of such error is questionable, due to an insufficient explanation of similar positive error in the control groups. The relationship of time perception to speed of body morement warrants further investigation utilizing longer TCs and a wider range of rotation speeds

\section{RLFEREXCES}

ARONS. M. \& LONDOX. H. Correting for compernsution ill studits of fiule estmution. Psychonomic Science. 1969.17.319.320.

BARTLEY. S. Principles of perception. New York: Harper \& Brothers. 1958.

FRAISSE, P. The psychologi of time. New York: Harper \& Row. 1963.

GRAYBIEL, A.. KERR, W.. \& BARTLFY. S. Stimulus thresholds of the semicircular canals as a function of angular acceleration. Amsrican Journal of Psychology, 1948.61.21-36.

HIRST, J., PICKFORD, R., \& WYBLRN, G. Human senses and perception. London: Oliver \& Body, 1964

HORNSTEIN. A.. \& ROTTER. G. Research methodology in temporal perception. Journal of Experimental Pyychology, 1969. 79. $561-564$.
JOHSTON W. \& TAYLOR N A reriem of the phyolugical sfiect of angular accelerations.

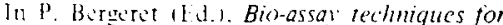
human centrituges and physiological effects of accelctation. New rork: Pergamon Press. 1965. Pp. 23.34.

LOFHLIX. J. The influence of difterent activities upon the apparent length of time. Pischological Monographs. 1959. 7314. Whole No. 474 .

TRIPLIFT, D. The relation between the physical pattern and the reproduction of short temporal intervals, Ps chological Monographs. 1931.201 .285

WF NDT G. Vestibular funtions. In S. S. Stevens (Ld.). Haidbook of experinchtal psichologi. rew York: Wiler, 1951. Pp. 1191-1223.

WOODROW. H. Individual differences in the reproduction of temporal intervals. American Journal of Psychology, 1933.45.271+281.

\title{
The effect of stimulus type on formal similarity between stimuli and their primary associations
}

\author{
STEVEN M. ROSEN. Staten Island Community College. N.Y. 10301 \\ and \\ PHYLLIS GREENHOLSE. Brooklyn College. Brooklyn. N.Y. 11210
}

The experiment investigated the effect of stimulus type on fomal similarity (FS) between stimuli and $\mathrm{Ss}^{\circ}$ primary associations to them. Word (W) and nonsense (NS) stimuli were employed. FS was defined as percentages of letters appearing in the same ordinal positions in associations as in stimuli. Results indicated that FS between NS stimuli and their primaries consistently exceeded chance while that between $W$ stimuli and their primaries exceeded chance in only one of six cases.

Noble (1952) developed an index of meaningfulness, $m$, which has achieved wide usage among researchers of verbal behavior $(m=$ mean number of continuous associations evoked to a stimulus in a 60-sec interval). But Schulz \& Hopkins (1968) noted that Voble and his followers (e.g.. Noble \& Parker, 1960) paid little attention to the nature of associations. being chiefly concerned with reliable measurement of their numbers. Schulz \& Hopkins obtained the primary associations of 96 disyllables previously scaled for $m$ by Noble (1952). They found that a tendency for the primaries to have the same initial letters as their stimuli was inversely related to the $m$ of the stimuli. The present research attempts to test a proposed explanation for this finding.

Coble used two types of stimuli in his research: Words (W) and nonsense (NS). It is proposed that Ss respond to $\mathrm{W}$ and NS stimuli on different bases. In their previous experiences with words. Ss have learned the objects, events, or attributes to which they refer. Associations to $\mathrm{W}$ stimuli are based on these semantic referents. But Ss have not previously encountered NS stimuli and, therefore, such stimuli cannot refer directly to $\mathrm{Ss}^{\circ}$ prior experiences. Consequently, Ss respond to NS stimuli on a formal basis, i.e.. in terms of the similarity of their letters and/or sounds to known words. It is hypothesized that formal similarity (FS) between a W stimulus and Ss' associations to it does not exceed chance, while that between a NS stimulus and Ss' associations to it is significantly greater than chance.

This hypothesis accommodates Schulz \& Hopkins's results. They found that stimuli 
and their assuciations tended to have the same first letters. particularly when these stimuli had low $m$ values. The XS stimuli used by Schulz \& Hopkins had uniformly lower $m$ values than the W stimuli. According to the hypothesis. the prevalence of first letter coincidences among low $m$ stimuli resulted from a formal mode of response to NS stimuli. METHOD

The Ss consisted of 100 Brooklyn College undergraduates in an introductory psychology course.

A set of six five-letter $W$ stimuli and six such NS stimuli were selected from Olson \& Schwartz's (1967) tables. Each S was presented with every stimulus.

Noble's (1952) procedure was generally followed. W and NS stimuli were presented to Ss in booklet form. Each stimulus was printed on a separate sheet in the booklet. It appeared once at the top of the page and was repeated 13 times in each of three columns. Ss were instructed to write every response to the stimulus on a line provided just to the right of each repetition. The order of presentation of stimuli was varied randomly.

Ss were tested in a lecture room during a single session. They were told they would be presented with both $W$ and NS stimuli and were instructed to write down as many as possible of the words that each stimulus brought to mind. They were given two practice items. one $\mathrm{W}$ and one NS, before beginning the experimental stimuli. Ss responded to each stimulus for $60 \mathrm{sec}$. The interitem interval was $5 \mathrm{sec}$.

\section{RESULTS AND DISCUSSION}

Goss \& Nodine's (1965) method was used to obtain FS between stimuli and Ss' primary associations to them. The stimulus and its primary were placed side by side at their first letters. The number of common letters in the same ordinal positions was tallied and divided by the total number of letters in the stimulus and then, separately, by the total number of letters in the primary. FS was the average of these two quotients.

Of $100 \mathrm{Ss}, 12$ were elininated for not following instructions. For each remaining $\mathrm{S}$, mean FS was computed for the six NS stimuli and compared with that obtained for the six W stimuli. In 83 of 88 cases, mean FS for the NS stimuli exceeded that for the W stimuli.

Table 1 shows FS computed by stimulus. The first primary is the response given most frequently as the first association to the stimulus. The FS of the first primary to the stimulus is shown in the table. While every NS first primary is, to some extent. formally similar to its stimulus. five of six $W$ first primaries have no formal similarity to their stimuli.
A baseline FS was obtained for each stimulus by pairing each $N$ times $(N=88)$ with words selected randomly from the Thorndike-Lorge (1944) word count. The baseline represented a chance level of FS against which the actual FS data could be compared. A large proportion of cases of zero FS was observed for both the baseline and actual data. Consequently, the data analysis was conducted at a nominal level of measurement. The proportion of cases of greater-than-zero FS obtained in the actual sample was compared with that found in the baseline by computing a chi square for each stimulus. Chi-square values are shown in Table 1.

\section{Table 1}

Formal Similarity (FS) of Primary Associations to $\mathrm{W}$ and NS Stimuli

\begin{tabular}{llcc} 
Stimulus & \multicolumn{1}{c}{$\begin{array}{c}\text { First } \\
\text { Primary }\end{array}$} & $\begin{array}{c}\text { First } \\
\text { Primary } \\
\text { FS }\end{array}$ & $\begin{array}{c}\text { Chi } \\
\text { Squarea }\end{array}$ \\
\cline { 1 - 2 } Catef & \multicolumn{2}{c}{ NS Stimuli } \\
Colav & Collage & .80 & $+38.86^{* * *}$ \\
Yuint & Joint & .50 & $+43.58^{* * *}$ \\
Mutro & Metro & .80 & $+55.62^{* * *}$ \\
Anory & Armory & .18 & $+40.42^{* * *}$ \\
Worpl & Warped & .55 & $+44.74^{* * *}$ \\
& \multicolumn{1}{c}{ W Stimuli } \\
Acted & Played & .00 & \\
Lambs & Sheep & .00 & +0.03 \\
Moist & Wet & .00 & -10.10 \\
Hangs & Picture & .00 & +0.02 \\
Taped & Recorded & .00 & $-4.04^{* *}$ \\
Clays & Plays & .80 & $+22.66^{* * *}$
\end{tabular}

${ }^{a_{\text {Comparison }}}$ of $F S$ of all actual primaries with chance level.

${ }^{*} p<.05,{ }^{* *} p<.005,{ }^{* * *} p<.001$

For each NS stimulus, the actual FS significantly exceeded the baseline with $\mathrm{p}<.001$. Yet, the only $W$ stimulus whose actual FS significantly exceeded its baseline was "clays." This latter outcome is attributed to the high FS between "clays" and its first primary, "plays." But these two words are clearly not related to each other on only a formal basis (e.g., one plays with clays). Since none of the other W stimuli yielded significant positive chi squares, perhaps the high FS between "clays" and "plays" is merely coincidental to their obvious semantic relationship.

In two cases, "moist" and "taped," actual FS was significantly less than the baselines, as indicated by negatively signed cli squares in Table 1. In the actual data, certain associations recurred frequently as primary responses to a given stimulus. But the baseline data was derived from 88 chance pairings of each stimulus with words taken from a list of approximately 20,000 entries. Consequently, the probability of a recurrence of a baseline response was relatively small. and therefore. the number of different responses to a given stimulus was greater for the baseline than for actual data $\mathrm{The}_{2}$ significant negative chi squares obtained for "moist" and "taped" resulted from the predominance in the actual data of a relatively small number of recurring primaries which had no FS to their stimuli. The distribution of primaries to "moist" is a particularly striking example of this phenomenon. Eighty-eight Ss gave only 16 different primary associations to "moist." Of these, only two responses, "wet" and "damp" accounted for $79 \%$ of the data (the number of different primaries to other W stimuli ranged from 28 to 47 and no two primaries could account for more than $43 \%$ of the responses to a given stimulus). Note that neither "wet" nor "damp" bear any FS to "moist."

It is concluded that the data provided strong evidence for the hypothesis that $\mathrm{Ss}$ respond to NS stimuli on a formal basis but nonformally to $W$ stimuli. This result accounts for the inverse relationship obtained by Schulz and Hopkins between $m$ and the tendency for the first letters of stimuli to correspond with those of their primary associations. But the implication of the present finding is broader. Noble and his followers disregarded the nature of associations in measuring the meaningfulness $(m)$ of $\mathrm{W}$ and NS stimuli. Consequently, a NS stimulus which evoked more associations than a $\mathrm{W}$ stimulus would paradoxically be judged more meaningful than the $W$ stimulus. Yet, the paradox is dispelled if it is recognized that $S$ s respond to $W$ and NS stimuli on different bases. Words evoke responses based upon Ss' prior experiences. But Ss have not previously encountered NS stimuli and, hence, cannot respond to them in these terms. Instead, responses to NS stimuli are based on the similarity of their letters and/or sounds to known words.

\section{REFERENCES}

GOSS, A. E., \& NODINE, C. F. Paired-associates learning. New York: Academic Press, 1965.

NOBLE, C. E. An analysis of meaning. Psychological Review, 1952, 59, 42 1-430.

NOBLE, C. E.. \& PARKER, G. V. The Montana scale of meaningfulness. Psychological Reports, 1960, 7, 325-331

OLSON, R.. \& SCHWARTZ, R. Single and multiple solution five-letter words. Psychonomic Monograph Supplements, 1967 . 2(8, Whole No. 24).

SCHULZ, R. W., \& HOPKINS, R. H. Free-association responses to verbal stimuli of varying meaningfulness as a function of presentation mode. Journal of Verbal Learning \& Verbal Behavior, 1968, 7.737-745.

THORNDIKE, E. L., \& LORGE, I. The teacher's word book of 30.000 words. New York: Bureau of Publications. Teachers College, Columbia Lniversity. 1944. 